1. MBBS, FCPS (Urology) Consultant Urologist

Pir Abdul Qadir Shah Institute of Medical Sciences.

2. MBBS, FCPS (General Surgery)

Senior Clinical Fellow Liver

Transplant Surgery

Pir Abdul Qadir Shah Institute of

Medical Sciences,

Gambat, Khair Pur Mirs.

3. MBBS, MS (General Surgery)

Senior Clinical Fellow Liver

Transplant Surgery

Pir Abdul Qadir Shah Institute of Medical Sciences.

4. MBBS, FCPS (Urology) Consultant Urologist

Sindh Institute of Urology and

Organ Transplantation.

5. MBBS, FCPS (Urology)

Consultant Urologist

Sindh Institute of Urology and

Organ Transplantation.

6. MBBS, FCPS (Urology)

Consultant Urologist

Indus Hospital Muzaffargarh.

Correspondence Address:

Dr. Zulfiqar Ahmad

Department of Urology

Pir Abdul Qadir Shah Institute of

Medical Sciences.

drzulfi_ahmad@yahoo.com

Article received on:

09/03/2021

Accepted for publication:

19/07/2021

\section{Comparison of stone clearance rate in patients with distal ureteric stones, undergoing URS with and without a safety guide wire.}

Zulfiqar Ahmad ${ }^{1}$, Kaleem Ullah' ${ }^{2}$ Bilal Ahmed ${ }^{3}$, Safdar Saeed ${ }^{4}$, Usman Qamar $^{5}$, Pardeep Kumar

ABSTRACT... Objective: To compare stone clearance rate in patients with distal ureteric stones, undergoing URS with safety guide wire and without safety guide wire. Study Design: Randomized Clinical Trial study. Setting: Department of Urology, Pir Abdul Qadir Shah Institute of Medical sciences. Period: January, 2020 to December 2020. Material \& Methods: The study patients fulfilling the inclusion criteria were divided into two groups using the lottery method. Group A: Patients underwent URS with insertion of safety guidewire (SGW). Group B: These patients underwent URS without safety guidewire (SGW). Patients in both groups were compared for stone clearance. Results: Mean age in Group A was 37.79 \pm 12.44 years and in Group B were 33.31 \pm 11.48 years. Group wise distribution of gender showed $79(73.83 \%)$ male and 28 (26.17\%) females in Group A and 70(65.42\%) male and 37 female (34.57\%) in Group B. In comparison of both groups, $65.42 \%$ stone clearance was noted in Group A while $78.50 \%$ stone clearance was found in Group B and $p$-value found to be significant $(P=0.033)$. Conclusion: Our study concluded that stone clearance in patients with distal ureteral stones undergoing URS without SGW is higher in comparison to URS with SGW, without any added advantage.

Key words: $\quad$ Safety Guidewire, Ureteric Stone, Ureteroscopy, Ureteral Calculi.

\section{INTRODUCTION}

Ureteroscopy (URS) is nowadays considered procedure of choice for ureteral stones removal, because of development of small semi-rigid/ flexible ureteroscopes and improvement in lithotripsy devices. ${ }^{1}$ URS with a safety guidewire (SGW) allows easy placement of a ureteral stent for managing complication like ureteric injury. ${ }^{2,3}$

However, some researchers recommend that using ureteroscope without a SGW frequently facilitates access, manipulation and basketing of stones. ${ }^{4,5}$ But on the other hand some recommend the use of a SGW for patient safety. ${ }^{6}$

Study conducted by Ulvik et al. found higher stone clearance rate of $85.9 \%$ in patients without SGW compared to $71.7 \%$ in patients in whom SGW was used. ${ }^{7}$ This study questioned the routine use of safety guidewire in all URS procedures because of low stone clearance rate. Moreover a recent metaanalysis failed to reach any conclusion about the use of SWG during routine URS procedure. This meta-analysis recommended further comparative studies on stone clearance rate in patients with distal ureteric stones, undergoing URS with and without SGW. ${ }^{7,8}$

As no local studies were found in the literature. So, this study was aimed to compare the stone clearance rate in patients with distal ureteric stones undergoing URS with and without SGW. The results of this study will help us make local guidelines.

\section{MATERIAL \& METHODS}

This Randomized Clinical Trial was done at Department of Urology, Pir Abdul Qadir shah 
institute of Medical Sciences from 1st January 9, 2020 to $31^{\text {st }}$ December, 2020. Study duration was 12 months. Sample size for this study was 107 patients in each group. So a total number of 214 patients were selected for this study through nonprobability consecutive Sampling technique.

The inclusion criteria include Patients having age 18-60 years with either gender with distal ureteric stones with a stone size of $<10 \mathrm{~mm}$, and duration of $<1$ year.

Patients with untreated urinary tract infections (UTI) diagnosed on routine urine analysis and culture were excluded because these conditions can affect stone clearance rate. Study was conducted after approval from ethical committee of the hospital (PASQJIMS/IRB/712). Written and verbal informed consent was taken from all patients.

The study patients were divided into two equal groups using the lottery method. Patients were asked to select one from folded papers with the name of treatments and thus divided into two equal groups depending upon the folded paper chosen by them. Group A: Patients underwent URS with insertion of SGW. Group $B$ : These patients underwent URS without SGW. Consultant urologists with at least 3 years' postfellowship experience were asked to do the URS with and without guidewire. Post procedure antibiotic coverage and analgesics were given for a period of 1 week post-surgery. The frequency of the stone clearance rate was recorded in both groups. patients were followed for six weeks.

All the collected information regarding stone clearanceand other relevant information regarding patient such as age, gender, BMI, duration of procedure and stone clearance were recorded on a pre-designed Performa. Data analysis was carried out using SPSS version 21.0. Mean+ SD was calculated for quantitative variables like age, BMI and duration of procedure. Categorical variables like gender, side of ureteral stones and frequency of stone clearance rate were presented as frequency and percentage. Chi-square test was used to compare stone clearance rate between groups.

\section{RESULTS}

Mean \pm SD of age in URS with SGW was $37.79 \pm 12.44$ and without SGW group was $33.31 \pm 11.48$ years with $P$ value of 0.007 .

In group wise distribution of gender, 79 (73.83\%) were male and 28 (26.17\%) were females in enrolled in Group A and 70(65.42\%) male and 37 female (34.57\%) were enrolled in Group B.

Mean \pm SD of duration of procedure in Group A was $33.91 \pm 11.20$ minutes and $31.91 \pm 10.22$ minute in Group B with non-significant p-value of 1.0 .

In distribution for side of ureteral stones, 46 (42.99\%), 63 (58.88\%) were on the right side and $61(57.01 \%), 44(41.12 \%)$ were on the left side of URS with and without SGW respectively.

In comparison of both group $65.42 \%$ stone clearance was noted in URS with SGW while $78.50 \%$ stone clearance was noted in URS without SGW and the comparison between both groups was found statistically significant $(P=0.033)$ while no intraoperative complications like uretic injury and bleeding recorded in both groups.

\section{DISCUSSION}

The use of SGW gives the advantage of timely stent placement in the case of significant ureteral perforation or bleeding prohibiting continuity of procedure..$^{9,10}$ However, literature showing the cumulative evidences for supporting the routine SGW usage during URS procedure is relatively weak (Grade C evidence). There is also a perception that regular and routine use of SGW may not be require and may be even harmful, because working without a SGW experience less friction and frequently facilitates scope manipulation, access, and making laser and basketing of stones easier. ${ }^{7,11,12}$ 


\begin{tabular}{|c|c|c|c|}
\hline & $\begin{array}{c}\text { Group A } \\
\text { (URS With Safety Guide } \\
\text { wire) }\end{array}$ & $\begin{array}{c}\text { Group B } \\
\text { (URS Without Safety Guide } \\
\text { wire) }\end{array}$ & P-Value \\
\hline Age & $37.79 \pm 12.44$ years & $33.31 \pm 11.48$ years & 0.007 \\
\hline Gender & $\begin{array}{l}M=79(73.83 \%) \\
\mathrm{F}=28(26.17 \%)\end{array}$ & $\begin{array}{l}M=70(65.42 \%) \\
F=37(34.57 \%)\end{array}$ & 0.18 \\
\hline BMI & $20.58 \pm 2.22$ & $21.81 \pm 2.35$ & 0.0001 \\
\hline Side of Ureteral stone. & $\begin{array}{ll}\text { Right }=46 & \text { Left }=61 \\
(42.99 \%) & (57.01 \%)\end{array}$ & $\begin{array}{lc}\text { Right }=63 & \text { Left }=44 \\
(58.88 \%) & (41.12 \%)\end{array}$ & 0.02 \\
\hline Duration of procedure & $33.91 \pm 11.20 \quad$ minutes & $31.91 \pm 10.22$ minutes & 1.0 \\
\hline $\begin{array}{l}\text { Intra-operative } \\
\text { complications }\end{array}$ & 00 & 00 & 00 \\
\hline Stone clearance & $70(65.42 \%)$ & $84(78.50 \%)$ & 0.033 \\
\hline
\end{tabular}

Moreover, in addition many authors have published their successful experiences with semirigid and flexible URS without a SGW usage for both renal and ureteric stones. ${ }^{12-14}$ The concept of historically longstanding ideology of "SGW always in endo-urology" might have originated from that time when instruments for Endo-urology were not much advanced. Nowadays, mini flexible digital scopes having deflection of 270 degrees, hydrophilic access sheaths, small laser fibers, nitinol baskets and hybrid guide wires have taken procedure safety and precision to a new level. However, despite this much technological progress, unpredictable complications can occur during these endoscopic interventions especially in cases with abnormal anatomy, ureteric narrowing and edema, suboptimal visualization, and longstanding obstructive stones. Therefore, recommendations is to use a SGW whenever a difficult procedure is encountred. ${ }^{11,12}$

In our study, the mean age of patients was $37.79 \pm 12.44$ and $33.31 \pm 11.48$ Group "A" and Group "B", respectively. Our results are in accordance with the findings of study conducted by Buscarini $\mathrm{M}^{15}$ who documented the mean age of the patients as $33 \pm 10.56$ years.

In the present study, a significant difference was noted in stone clearance in both groups, $65.42 \%$ versus $78.50 \%$ in URS with SGW and URS without SGW, respectively, with a significant $\mathrm{p}$-value of 0.033 . Also, the study conducted by
Ulvik et al.7 found a higher stone clearance rate of $85.9 \%$ in patients without SGW compared to $71.7 \%$ in patients in whom SGW was used. They also reported no significant differences between both groups regarding the primary outcome, rate of the successful passage of scope through the ureteral orifice, successful access to the ureteric calculus, and ability to place a stent when needed. ${ }^{7}$ However, further Studies showing larger data are needed for clarification of this, particularly in complex cases. Good evidence supporting the routine use of an SGW is lacking in the literature, and the recommendations are based upon expert opinions. ${ }^{16}$

Earlier reports do recommend using an SGW while facing ureteric strictures, impacted stones, and heavy stones burden ${ }^{17-19}$ or in the case of inexperienced surgeons. ${ }^{6,20}$ It is found that URS performed by an inexperienced surgeon is associated with a higher complication rate. ${ }^{21}$ while, other studies showed no significant difference regarding the incidence of intraoperative URSrelated complications performed by resident surgeons, suggesting that the use of SGW may not be necessary even when less experienced surgeons perform URS. ${ }^{22,23}$

Contrary to our expectations, significant difference was not observed in duration of procedure between the two groups $(33.91 \pm 11.20$ minutes versus $31.91+10.22$ minutes). Although repeated attempts of pushing the guidewire back in the 
ureter take more time. We also experienced that with fast flow of irrigation fluid the procedure can be performed more efficiently and possibly faster resulting in improved vision.

\section{CONCLUSION}

Our study concluded that stone clearance in patients with distal ureteral stones undergoing URS without SGW is higher in comparison to URS with SGW, without any added advantage. So, URS without SGW in experienced hands give excellent results without any risk. We recommend further studies with large sample size to confirm the above mention findings of this study.

Copyright@ 19 July, 2021.

\section{REFRENCES}

1. De La Rosette J, Denstedt J, Geavlete P, Keeley F, Matsuda T, Pearle M, Preminger G, Traxer O, CROES URS study group. The clinical research office of the endourological society ureteroscopy global study: Indications, complications, and outcomes in 11,885 patients. Journal of Endourology. 2014 Feb 1; 28(2):131-9.

2. Whitehurst LA, Somani BK. Semi-rigid ureteroscopy: Indications, tips, and tricks. Urolithiasis. 2018 Feb; 46(1):39-45.

3. Bagley $\mathrm{DH}$, Kuo RL, Zeltser IS. An update on ureteroscopic instrumentation for the treatment of urolithiasis. Current opinion in urology. 2004 Mar 1; 14(2):99-106.

4. Ulvik $\varnothing$, Wentzel-Larsen T, Ulvik NM. A safety guidewire influences the pushing and pulling forces needed to move the ureteroscope in the ureter: a clinical randomized, crossover study. Journal of endourology. 2013 Jul 1; 27(7):850-5.

5. Patel SR, McLaren ID, Nakada SY. The ureteroscope as a safety wire for ureteronephroscopy. Journal of endourology. 2012 Apr 1; 26(4):351-4.

6. Dutta R, Vyas A, Landman J, Clayman RV. Death of the safety guidewire. Journal of endourology. 2016 Sep 1; 30(9):941-4.

7. Ulvik $\varnothing$, Rennesund K, Gjengstø P, Wentzel-Larsen T, Ulvik NM. Ureteroscopy with and without safety guide wire: Should the safety wire still be mandatory? Journal of endourology. 2013 Oct 1; 27(10):1197-202.
8. Molina Junior WR, Pessoa RR, Silva RD, Gustafson D, Nogueira L, Meller A. Is a safety guidewire needed for retrograde ureteroscopy?. Revista da Associação Médica Brasileira. 2017 Aug; 63(8):717-21.

9. Bagley $\mathrm{DH}$, Kuo RL, Zeltser IS. An update on ureteroscopic instrumentation for the treatment of urolithiasis. Current opinion in urology. 2004 Mar 1; 14(2):99-106.

10. Kumar PV, Keeley Jr FX, Timoney AG. Safe flexible ureterorenoscopy with a dual $\square$ lumen access catheter and a safety guidewire. BJU international. 2001 Oct; 88(6):638-9.

11. Patel SR, McLaren ID, Nakada SY. The ureteroscope as a safety wire for ureteronephroscopy. Journal of endourology. 2012 Apr 1; 26(4):351-4.

12. Eandi JA, Hu B, Low RK. Evaluation of the impact and need for use of a safety guidewire during ureteroscopy. Journal of endourology. 2008 Aug 1; 22(8):1653-8

13. Johnson GB, Portela D, Grasso M. Advanced ureteroscopy: Wireless and sheathless. Journal of endourology. 2006 Aug 1; 20(8):552-5.

14. Moran ME, Bratslavsky G. Changing paradigm during routine flexible ureteroscopy and holmium: YAG laser lithotripsy: Need for safety wires. J Endourol. 2003;17(1):A225

15. Buscarini M, Conlin M. Update on flexible ureteroscopy. Urologia internationalis. 2008; 80(1):1-7.

16. Holmes RP, Goodman HO, Assimos DG. Contribution of dietary oxalate to urinary oxalate excretion. Kidney international. 2001 Jan 1; 59(1):270-6.

17. Holden T, Pedro RN, Hendlin K, Durfee W, Monga M. Evidence-based instrumentation for flexible ureteroscopy: A review. Journal of endourology. 2008 Jul 1; 22(7):1423-6.

18. Kronenberg $P$, Traxer $O$. Are we all doing it wrong? Influence of stripping and cleaving methods of laser fibers on laser lithotripsy performance. The Journal of urology. 2015 Mar; 193(3):1030-5.

19. Traxer O, Wendt-Nordahl G, Sodha H, Rassweiler J, Meretyk S, Tefekli A, Coz F, Jean J. Differences in renal stone treatment and outcomes for patients treated either with or without the support of a ureteral access sheath: The Clinical Research Office of the Endourological Society Ureteroscopy Global Study. World journal of urology. 2015 Dec; 33(12):2137-44. 
20. Stamatelou KK, Francis ME, Jones CA, Nyberg Jr LM, Curhan GC. Time trends in reported prevalence of kidney stones in the United States: 1976-1994. Kidney international. 2003 May 1; 63(5):1817-23.

21. Lo SS, Johnston R, Al Sameraaii A, Metcalf PA, Rice $\mathrm{ML}$, Masters JG. Seasonal variation in the acute presentation of urinary calculi over 8 years in Auckland, New Zealand. BJU international. $2010 \mathrm{Jul}$; 106(1):96-101.
22. Türk C, Petřík A, Sarica K, Seitz C, Skolarikos A, Straub M, Knoll T. EAU guidelines on interventional treatment for urolithiasis. European urology. 2016 Mar $1 ; 69(3): 475-82$.

23. Bagley $\mathrm{DH}$, Kuo RL, Zeltser IS. An update on ureteroscopic instrumentation for the treatment of urolithiasis. Current opinion in urology. 2004 Mar 1; 14(2):99-106.

\begin{tabular}{|c|l|l|l|}
\hline \multicolumn{3}{|c|}{ AUTHORSHIP AND CONTRIBUTION DECLARATION } \\
\hline No. & \multicolumn{1}{|c|}{ Author(s) Full Name } & Contribution to the paper & Author(s) Signature \\
\hline 1 & Zulfiqar Ahmad & $\begin{array}{l}\text { Statistical expertise and } \\
\text { Result compilation. } \\
\text { Acquisition of data. }\end{array}$ \\
\hline 3 & Kaleem Ullah & Bilal Ahmed & Drafting of Manuscript. \\
\hline 4 & Safdar Saeed & Review of Discussion. \\
\hline 5 & Usman Qamar & Interpretation of data. \\
\hline
\end{tabular}

